\title{
Pós-colonialidade, pós-escravismo, bioficção e con(tra)temporaneidade
}

Denise Carrascosa ${ }^{1}$

\begin{abstract}
Tem essa tal coisa do sofrimento de pessoas negras serem um sumário de tudo que filósofos e profetas já disseram, disse ela. Eles disseram: "Nunca pense em termos de Eu e Meu. Isso é a morte". Mas eles disseram isso assim belamente, sob a sombra de árvores sagradas. Não teve qualquer impacto geral sobre a humanidade. Foi para um círculo exclusivo de seguidores. As pessoas negras aprenderam isso abruptamente porque foram as vítimas vivas da ganância inspirada pelo Eu e pelo Meu e pelo vá pro inferno, cachorro!

(Bessie Head, A question of power)
\end{abstract}

\section{O compromisso com a teoria uma vez mais}

Em tempos ditos pós-modernos, os processos de escrita de si são estudados mais como configurações de dispositivos de produção subjetiva do que de representação do eu. ${ }^{2}$ A performatividade da linguagem como mecanismo agregado à engrenagem da subjetivação não constitui novidade ao pensamento, entretanto. Já desde a reverberação da psicanálise lacaniana e das pesquisas de Austin e Searle no campo dos estudos linguísticos, bem como do pensamento filosófico heideggeriano, pensa-se o sujeito como ser produzido na linguagem. Portanto, não como instância estanque aprioristicamente existente ou revelada em produto final, e sim como zona de ruptura e fragmentação, relação entre um si e um outro produzida na rede ininterrupta de significantes da cultura.

Na contemporaneidade, a questão da produção de si se revigora ao pensamento filosófico e da crítica da cultura a partir das reverberações do pensamento nietzschiano via pós-estruturalismos vários, na medida de um jogo discursivo que deseja flagrar, nas produções literárias, por exemplo, um voltar a si em forma de jogo ambivalente entre dispersão e

\footnotetext{
${ }^{1}$ Doutora em teorias e crítica da literatura e da cultura e professora da Universidade Federal da Bahia (UFBA), Salvador, BA, Brasil. E-mail: denise.carrascosa@ufba.br

${ }^{2}$ Comunicação apresentada na mesa-redonda "Narrativas pós-coloniais e escrita de si”, no âmbito do Seminário de Estudos sobre o Espaço Biográfico: desafios da bioficção, realizado entre 20 e 22 de novembro de 2013 na Universidade Federal da Bahia.
} 
convergência estratégicas. Sai do foco a desestrutura do sujeito como índice de valor artístico, roubando a cena o jogo intermitente de forças centrífuga e centrípeta na poética da hifenização e do intervalo, que tem constituído os parâmetros estéticos de avaliação das produções artísticas. Categorias conceituais de análise como "espaço biográfico", "autoficção", "bioficção", "conficção", entre outras cuja terminologia deriva de logística semelhante, emergem para dar forma crítica às dinâmicas das produções literárias a partir de tais parâmetros, entrando na ordem do discurso celebratório das poéticas de descentramento do sujeito contemporâneo.

Instigada por essa célere produtividade discursiva e, ao mesmo tempo, caucionada pelo gramsciano "pessimismo do intelecto", resolvo perguntar ao meu próprio curso de pensamento: "quanto de técnico, quanto de político" há naquilo que estamos conceituando e produzindo sob a categoria anfíbia da "bioficção"? Pois a minha frequência assídua nas paragens da teoria e práxis pós-colonial, seja como professora de literaturas de língua inglesa, seja como sujeito de experiência de um país pós-colonial e pós-escravista, ${ }^{3}$ coloca-me em contínua posição de desconfiança e desconforto em relação às problematizações e categorias teóricas que emergem e migram desde o além-mar europeu.

Ler e ensinar a partir do livro The empire writes back me deixa alerta à definição introdutória da relação entre pós-colonialidade e teoria:

A ideia de uma "teoria literária pós-colonial" emerge da inabilidade da teoria europeia em lidar adequadamente com as complexidades e proveniência cultural variada da escrita póscolonial. As próprias teorias europeias emergem a partir de tradições culturais particulares que ficam escondidas pela falsa noção do "universal". Teorias de estilo e gênero, pressupostos sobre características universais da linguagem, epistemologias e sistemas de valor são radicalmente questionados pelas práticas de escrita pós-colonial (Ashcroft et al., 1989, p. 11, tradução nossa).

\footnotetext{
${ }^{3}$ Chamo de sociedade "pós-escravista", a partir do local brasileiro de experiência histórica, aquela que se constituiu econômica e imaginariamente sobre as bases da escravização dos mais diversos povos indígenas e africanos e que precisa lidar, ainda após a abolição oficial do violento regime opressor, com a reemergência contínua das tensões cotidianas produzidas entre traços intensos dos regimes simbólicos recalcados e subalternizantes, em uma relação de forças que se reatualiza e intercambia posições e reverberações performativas ininterruptamente.
} 
Diante dessa premissa, devemos perguntar quanto de um europeísmo universalista ainda fica como traço residual nessas categorias teóricas nomeadas a partir do desejo de suspensão de fronteiras entre realidade e ficção, da vontade de dissolução da unidade discursiva do indivíduo? Essa questão assim delimitada parece soar repetitiva de uma problemática que assombra intelectuais em todas as nações pós-coloniais, incluindo o Brasil e seus debates já antigos sobre dependência intelectual. Entretanto, se acionada com certo olhar estratégico e menos nacionalmente centrado, pode encontrar uma conexão com a circunstância histórico-discursiva que permite a emergência de um pensamento pós-estrutural na Europa da segunda metade do século XX.

Isto é, o pensamento europeu que problematiza certas unidades operacionais e produtivas de discurso, tais como o "sujeito", pode ser (e está sendo) pensado, em sua genealogia, como geopoliticamente articulado aos movimentos de independência nos territórios então coloniais, às ideias e práticas aí produzidas e disseminadas por movimentos sociopolíticos e artísticos de várias ordens e, inclusive, pelas pressões econômicas envolvidas nos processos de migração periferiacentro, que desestabilizaram a economia das forças nos mundos imperiais e coloniais anglófonos, francófonos e lusófonos. A partir de The empire writes back, a citação que segue me incita a fazer essa afirmação:

Paradoxalmente, entretanto, a expansão imperial teve um efeito radicalmente desestabilizador de suas próprias questões e poder. Ao empurrar o mundo colonial para as margens da experiência, o "centro" levou a consciência para além do limite no qual o monocentrismo em todas as esferas de pensamento poderia ser aceito sem questionamento. Em outras palavras, o processo de alienação que inicialmente serviu para relegar o mundo pós-colonial à margem, voltou-se contra si próprio e agiu para fazer aquele mundo transpor uma barreira mental em direção a uma posição a partir da qual toda experiência poderia ser vista como descentrada, plural e multifacetada. A marginalidade, portanto, tornou-se uma fonte de energia criativa sem precedentes. $O$ ímpeto ao descentramento e pluralismo sempre esteve presente na história do pensamento europeu e alcançou o seu mais recente desenvolvimento com o pós-estruturalismo. Mas a situação das sociedades e culturas marginalizadas colocou-as nesta posição muito mais cedo e mais diretamente (Ashcroft et al., 1989, p. 12, tradução nossa). 
Nesse influxo de pensamento, o que desejo rearticular, portanto, é a relação entre pensamento europeu e pensamento pós-colonial brasileiro, retensionando-a do ponto de vista de um diálogo que encontre seu curso, não em uma bilateralidade sintética, mas em uma triangulação multivalente que passará por um eixo sul-sul de práticas teóricas. Nas palavras prolíficas de Homi Bhabha, o compromisso com a teoria é indispensável enquanto

compreendermos a tensão no interior da teoria crítica entre sua delimitação institucional e sua força revisionária. A referência contínua ao horizonte de outras culturas que mencionei anteriormente é ambivalente. É um lugar de citação, mas é também um signo de que essa teoria crítica não pode manter para sempre sua posição na academia como o fio cortante antagônico do idealismo ocidental. $O$ que se requer é demonstrar um outro território de tradução, um outro testemunho da argumentação analítica, um engajamento diferente na política de e em torno da dominação cultural (Bhabha, 2003, p. 60).

Até onde alcanço, a "força revisionária" da teoria crítica que nutre as discussões em torno do conceito de "bioficção" e afins precisa tecer a malha que conecta suas produções (nas mais diversas linguagens e suportes) aos diversos modos contemporâneos de produção econômico-simbólica da subjetividade, inclusive e principalmente aos subalternizantes.

\section{Teoria pós-estrutural do sujeito: modos de usar}

A noção de "espaço biográfico" (Arfuch, 2010), revisora do conceito de "pacto autobiográfico" (Lejeune, 2008), ambas as funções teóricas derivantes das premissas que orbitam em torno dos conceitos ligados ao "bioficcional" pertencem ao território epistemologicamente operacionalizado pelo pensamento pós-estrutural europeu, notadamente no que concerne à questão da produção subjetiva contemporânea. Tal grade conceitual atualiza, no campo do literário, aquilo sobre o que Gilles Deleuze, já resenhando um para-além do pensamento foucaltiano, pondera:

A luta por uma subjetividade moderna passa por uma resistência às duas formas atuais de sujeição, uma que consiste em nos individualizar de acordo com as exigências do poder, outra que consiste em ligar cada indivíduo a uma identidade sabida e 
conhecida, bem determinada de uma vez por todas. A luta pela subjetividade se apresenta então como direito à diferença e direito à variação, à metamorfose (Deleuze, 2005, p. 113, grifo nosso).

Esse pensamento hifenizado entre intelectuais do chamado pósestruturalismo francês nos fornece um flagrante nítido da exata medida em que entra em ação a tal "força revisionária" capaz da reversão do centramento teórico do pensamento europeu e suas implicações cotidianamente políticas, tais como a demanda performativamente repetida da existência de sujeitos paralisados em suas individualidades úteis.

No curso dessas questões, para além de Deleuze e Foucault, resolvo ler outras pessoas que releram Marx a partir de lugares mais geopoliticamente próximos ao meu, mas também um pouco mais "disciplinarmente" distantes. Talvez possa me assistir o Néstor García Canclini do seguinte parágrafo de Diferentes, desiguais e desconectados:

A desconstrução mais radical da subjetividade vem sendo realizada por procedimentos genéticos e sociocomunicacionais que favorecem a invenção e a simulação de sujeitos. Da robótica à clonagem, do travestimento de gênero ao fingimento de personalidades em jogos eletrônicos, a pergunta sobre o que significa, hoje, ser sujeito menos se altera do que se aproxima do princípio da dissolução (Canclini, 2005, p. 184).

O antropólogo argentino põe em jogo, no texto de qual vem o fragmento lido, uma tensão que me interessa muitíssimo entre a simulação politicamente apropriada do lugar de sujeito e a capitalização neoliberal da existência fluida do sujeito.

Isto é: o travestimento de gênero, por exemplo, pode ser lido como deslizamento político que tensiona as regras da heteronormatividade uma produtividade potente do jogo contemporâneo com o aprisionamento das subjetividades possíveis em regras de comportamento sexual. Por outro lado, o uso do processo de virtualização do subjetivo pelo mercado de bens simbólicos, em sua contraface utilitária e neoliberal, pode servir, em diversas situações cotidianas de consumo, por exemplo, à produção interessada de consumidores dóceis. Diante dessa outra visada, justifica-se a pergunta: será que damos continuidade a um certo pensar a produção estética desarticuladamente do modo de produção econômico, hoje global e desterritorializado, assim como tantos sujeitos cujo nomadismo festejamos? 
Pós-marxismos à parte, falemos agora de coisas antigas: de relações humanamente concebidas e de ética no espaço público. Criticando o atual "self tecnológico", Muniz Sodré, no livro Antropológica do espelho, afirma a condição do indivíduo contemporâneo "sob a égide das abstrações do universalismo jurídico e da economia monetária, relacionando-se basicamente em função do consumo e da produção" (2002, p. 162). "O ser comutável" tratar-se-ia de

um modo sistêmico de integração social caracterizado, do ponto de vista da reciprocidade das práticas, por atores e grupos sociais fisicamente ausentes no tempo e no espaço. Nele, homem e objeto são concebidos como feixes de relações institucionalmente habilitados por uma presença sistêmica ou espectral.

A "pele" com que se tocam os indivíduos fantasmáticos é uma prótese digitalizada que, na reciprocidade dita interativa, permite fazer economia da corporalidade natural e da personalidade total. Suas identidades, tendentes à multiplicidade e à fluidez, dependem cada vez mais de um tênue equilíbrio relacional entre qualidades diferentes, ou seja, do "valor da interface" (Sodré, 2002, p. 163).

Em que pesem os sutis traços de idealismo platônico que poderíamos flagrar hoje nessa crítica de Sodré (em um texto com mais de dez anos de idade, diga-se de passagem), o seu desdobramento nos faz ponderar sobre a disseminação das práticas de espetacularização, virtualização e/ou desmembramento do "eu" em sua articulação técnica com o modo de produção neoliberal tecnológico da contemporaneidade.

Diante desses outros flagrantes críticos, pode-se dizer que o pensamento social contemporâneo latino-americano sobre a problemática da subjetividade revisa e redesenha os limites da reflexão filosófica europeia pós-estrutural (e/ou as suas reverberações discursivas), instalando no binômio necessário unidadepoder/multiplicidade-contra-poder um jogo mais móvel, veloz e de possibilidades de capitalização inusitadas. Jogo este que solicita o campo teórico a partir de onde falo agora no sentido da questão inscrita na formulação e uso do conceito de "bioficção". Diante dessa provocação e para tornar mais nítida a tarefa, podemos situá-la e transformá-la em pergunta: na cena contemporânea de feroz globalização econômica e cultural, quais os desafios da chamada, pelo atual campo dos estudos literários, "bioficção"? 
Ainda buscando usufruir de territórios adjacentes e transversais ao nosso campo de problematização, desejo remeter-nos à última palestra proferida por um outro Canclini, aqui em Salvador, no último 25 de outubro, intitulada "Reinventar, desde a criação dos jovens, o desenvolvimento cultural".4 O Néstor García Canclini de Diferentes, desiguais e desconectados aqui já nos fala da potência de reinvenção cultural a partir da dinâmica contemporânea de produção laborativa dos jovens. Chama nossa atenção para as novas práticas culturais derivadas de uma geração de profissionais não profissionalizados que, no cotidiano assistemático dos seus trampos, principalmente a partir de seus computadores e conexões em rede, vão driblando o sistema neoliberal e predatório de produção de capital. Vão mobilizando sistemas simbólicos tensionadores da cultura mainstream desde dentro da cultura virtual. Colocam-se provisoriamente na rede de produção nômade de subjetividades, minando a captura mercadológica da escolha da profissão ou formação para profissão.

Pois bem, parece haver uma potência desviante aí, não? Uma potência que considera e tensiona o território aparentemente desorientado da geração de grana; dessa grana sem fronteiras; e dessa ciência também. Até onde enxergo, parece que sim. Pois bem, como pensar a chamada bioficção - esse deslimite profícuo entre o eu e o outro, o real e o ficcional, o um e o múltiplo - em relação a essas (e outras) (des)territorializações, não necessariamente vinculadas ao campo de produção literária? Trata-se de uma atualização textual da pergunta anterior, mas já em uma configuração menos fetichizante e mais fluida do conceito, que pode ganhar força nas margens do campo teórico a partir do qual falamos. Isto é, a partir deste ponto, não me parece suficientemente rentável colocar ao pensamento uma questão à função do conceito como centro irradiador de produtos. Mais profícuo pode ser procurar pensá-lo menos como conceito operatório na ordem do articulável/não articulável a tais ou quais produções literárias, por exemplo, e mais como funcionamento discursivo imbricado nas práxis sociais e produções culturais que estudamos, em zona de extensão e conexão com produções literárias.

\footnotetext{
${ }^{4}$ No âmbito do Fórum do Pensamento Crítico 2013: cultura e transformação social, realizado pela Secretaria de Cultura da Bahia e Fundação Pedro Calmon.
} 
No fluxo desse desejo, o jogo discursivo de uma teoria eficazmente crítica nos endereça aos múltiplos usos do trabalho bioficcional, nem sempre como espaço de remissão a certa autoria (espaço biográfico), mas também como potência do deslimite do "eu" como unidade de sentido e de produção de práticas culturais (em um viés antropológico). Assim, pode tornar-se possível lidar criticamente com os influxos instáveis dos jogos de poder movidos por tais práticas menos na medida da equação perene: hegemonia = unidade / contra-hegemonia = dispersão, do que derivaria um estatuto de valor hoje estruturalmente estável e criticamente ingênuo atribuível ao chamado bioficcional. Ao contrário, o que busco aqui pensar deseja abordar os diversos usos do "funcionamento" bioficcional transversalizado às práticas culturais de significação, nas fronteiras contemporaneamente solúveis entre arte e cultura, economia e política, identitário e plural.

\section{Pós-colonialidade, pós-escravismo, bioficção e con(tra)temporaneidade}

Se, por um lado, quisermos pensar as técnicas de centramento do sujeito como forma de aprisionamento dos nossos corpos em categorias úteis ao mercado de bens materiais e simbólicos, parece que muitas dessas biofiç̧ões que estamos estudando em nossa cena acadêmica contemporânea apresentam alguma potência de desvio, sim; muito embora eu fique quase sempre desconfiada de tudo aquilo que faz retornar sorrateiramente à instância de autor-idade de homens-de-classe-médiabrancos-heterossexuais-metropolitanos-falantes-do-português-global, nos jogos de poder continuamente tensos de uma sociedade pós-escravista e pós-colonial, assim como a defini anteriormente.

Por outro lado, podemos desejar pensar que as técnicas de produção subjetiva nem sempre são de centramento e captura, mas que muitas e muitas vezes, ao longo da história, no apagar de suas luzes e agora mesmo, nos bastidores de nossa contemporaneidade, produzem-se sujeitos descentrados como tecnologia de uso, controle e subalternização.

Vamos pensar nas prisões e nos manicômios. (Desejamos?)

Vamos pensar na escravidão. (Podemos?)

Vamos pensar na colonização. (Vamos?) 
Diante de tais demandas, é preciso e, talvez, incontornável, pensar localizadamente e, portanto, em zona de diferença negociada com o pensamento foucault-deleuziano sobre a problemática da subjetivação.

Em minha tese de doutoramento, interessada na produção da chamada "literatura prisional" no Brasil e tendo desenvolvido uma discussão sobre a produção da subjetividade capturadora do "marginal" e sua relação tensa com tal literatura como "escrita de si", cheguei a algumas formulações teóricas, dentre as quais:

[...] dois vetores de força que fazem parte de uma mesma zona de intensidades. Por um lado, um conjunto de práticas discursivas e técnicas que engendram a produção de posições imaginárias e sociais de sujeitos, controlando previamente suas possibilidades identitárias de existência e performances. De outro lado, um conjunto de estratégias discursivas e técnicas de resistência que pressionam a "naturalização" desses lugares imaginários préestabelecidos e possibilitam aos sujeitos executar performances diferenciais de produção ativa de um lugar social para si. A esses dois conjuntos de questões dei, respectivamente, os nomes de: "técnicas de si" e "políticas de si" (Carrascosa, 2009, p. 129).

$\mathrm{O}$ conceito do último Foucault das "técnicas de $\mathrm{si}^{5}$ fora instrumentalmente utilizado para pensar as produções subjetivas marginalizantes em foco e, como deriva teórica contrapontual, desdobradora e intensificadora da potência foucault-deleuziana do conceito, produzi a noção estratégica de "políticas de si" no sentido de lidar criticamente com a produção literária "prisional" então mapeada.

Um hiato de cinco anos favorece uma nova visada à questão assim tratada, mormente se pensada a partir do ponto de vista dos movimentos afro-diaspóricos e pós-coloniais. Uma espécie de "recapitalização" das dobras tecnológicas de produção de si parece se desenhar ao meu olhar teórico, intimamente conectado com meu lugar de produção subjetiva afro-diaspórica e pós-colonial. Pensar, como intelectual afro-brasileira, essa problemática gesta uma demanda outra de intervenções críticas, a começar pela necessidade de entender os processos de escravidão e colonização, como tecnologia de produção

\footnotetext{
${ }^{5}$ Definido por Michel Foucault no resumo do curso Subjetividade e Verdade (1980-1981) como: "procedimentos que, sem dúvida, existem em toda civilização, pressupostos ou prescritos aos indivíduos para fixar sua identidade, mantê-la ou transformá-la em função de determinados fins e isso graças a relações de domínio de si sobre si ou de conhecimento de si por si” (Foucault, 1997, p. 109).
} 
subjetiva dispersora e produtora de subjetividades utilmente despedaçadas, sem centro seguro de referência ou apoio sociopolítico.

Pensando com Frantz Fanon, tal encaminhamento fica mais historicamente tangível:

Enquanto o negro estiver em casa não precisará, salvo por ocasião de pequenas lutas intestinas, confirmar seu ser diante de um outro. Claro, bem que existe o momento de "ser para-o-outro", de que fala Hegel, mas qualquer ontologia torna-se irrealizável em uma sociedade em uma sociedade colonizada e civilizada. Parece que este fato não reteve suficientemente a atenção daqueles que escreveram sobre a questão colonial. Há, na Weltanschauung de um povo colonizado, uma impureza, uma tara que pró́be qualquer explicação ontológica. Pode-se contestar, argumentando que o mesmo pode acontecer a qualquer indivíduo, mas, na verdade, está se mascarando um problema fundamental. A ontologia, quando se admitir de uma vez por todas que ela deixa de lado a existência, não nos permite compreender o ser do negro. Pois o negro não tem mais de ser negro, mas sê-lo diante do branco. Alguns meterão na cabeça que devem nos lembrar que a situação tem um duplo sentido. Respondemos que não é verdade. Aos olhos do branco, o negro não tem resistência ontológica. De um dia para o outro, os pretos tiveram de se situar diante de dois sistemas de referência. Sua metafísica ou, menos pretensiosamente, seus costumes e instâncias de referência foram abolidos porque estavam em contradição com uma civilização que não conheciam e que lhes foi imposta (Fanon, 2008, p. 103-104, grifo nosso).

Esse excerto do então extraordinário ensaio Pele negra, máscaras brancas (anos 1950) continua atualíssimo nas realidades contemporâneas das sociedades pós-escravocratas da diáspora africana. Se tivermos o cuidado e a coragem de auscultarmos alguns de nossos parentes e/ou (se formos capazes) a nós próprios, não será difícil entender a luta cotidiana dos afrodescendentes em lidar com a hifenização constante em nossas identidades possíveis e sempre a um passo de se dissolver nas relações de poder cotidianas.

Os processos de descentramento subjetivo, desmobilização identitária e fragmentação da consciência já nos foi imposto e continua sendo em diversas cenas históricas e contemporâneas de produção da chamada "modernidade" ocidental. Éramos "sujeitos pós-modernos" antes de o jargão das ciências sociais falar disso, muito antes... Essas 
técnicas de disseminação de si são as mesmas empregadas pelos mecanismos estéticos "bioficcionais". Portanto, não parece haver qualquer invenção ou inovação teórico-ficcional, mas dobra, reutilização, recapitalização simbólica. Ressoa, então, uma pergunta e seus ecos: faz-se a dobra da dobra? Como se faz a dobra da dobra? Quem deseja fazê-la? Quem pode fazê-la? Quem a faz? ${ }^{6}$

Pois bem, tenho lido, de uns anos para cá, algumas escritoras de quem hoje dependo afetiva e existencialmente falando. Toni Morrison e Jamaica Kincaid são duas delas. Bessie Head é um tesouro recente.

Sim, essas companhias derivam, com maior ou menor intensidade, de um processo de produção subjetiva com o qual tenho um certo tipo de familiaridade - o processo de in-serção/de-serção diaspórica rompida ou fragmentada em uma certa instância socionacional.

Como mulheres que experimentaram processos de imigração entre fronteiras intra ou internacionais - inter-raciais e sociais, fomos produzidas, até certo ponto, na fatura da fratura. Nossos ossos só não andaram expostos porque somos das mulheres que sabem curar. Nossos processos de existência dependem de um cuidado de si que economiza forças de desvio e localização, multiplicidade e identidade estratégica, em uma palavra, (des)territorialização.

Vejamos...

Chloe Anthony Wofford só se torna a nossa Toni Morrison depois de um divórcio, após o qual transita, no solo norte-americano, de onde nasceu para o centro metropolitano nova-iorquino. Esse mesmo solo lhe foi ainda mais venenoso do que talvez o seja hoje, entre as décadas de 1930 e 1970, entre o seu nascimento civil e seu nascimento como escritora negra, com a publicação de seu primeiro romance - O olho mais azul (1970), no qual já experimenta um dispositivo narrativo em que a personagem principal funciona como reflexo ingrato no espelho tecido de desejos alienígenas e alienantes. Toni sempre se deixa apaixonar por uma outra personagem lateral e, ali, naquela aparição às vezes fugaz faz emergir uma outra possibilidade territorial para a migração do seu desejo. Uma produção contrapontual de si.

\footnotetext{
${ }^{6}$ Em ação aqui, o útil conceito deleuziano de dobra: "O lado de fora não é um limite fixo, mas uma matéria móvel animada de movimentos peristálticos, de pregas e de dobras que constituem um lado de dentro: nada além do lado de fora, mas exatamente o lado de dentro do lado de fora" (Deleuze, 2005, p. 104).
} 
Em Home, seu último romance, publicado em 2012, Frank - soldado que lutou aquilo que Morrison passa a chamar de "Guerra da Coreia", nos anos 1950 - deve voltar para casa após receber um bilhete sobre o estado de saúde terminal da irmã, Cee. Depois que a resgata das mãos de um uso biopolítico que leva seu corpo à esterilidade (metáfora da ciência branca exploratória do corpo negro nos Estados Unidos), os irmãos Frank e Cee voltam à cidade natal - Home - pintada com as cores de um sol infernal e mortificante.

Essa casa, que não é lar (em nada se assemelha à casa mencionada por Fanon no excerto recortado), nunca resgata o narrador intermitentemente interposto no romance. Esse personagem às vezes tem voz para conversar com sua escritora, dizendo-lhe daquilo que ela nunca saberá, dos seus pontos cegos, dos pontos cegos de ambos, como corpos negros úteis no mecanismo de produção do dinheiro pela guerra e pela ciência.

Essa extensão odiosa de sua consciência fraturada em forma de personagem nunca será salva. Contudo, mais uma vez, a aparição pretensamente inofensiva de uma personagem muito lateral chamada Ethel suplementará a narrativa traumática com uma cura. Ethel cozinha, costura, coloca Cee sob banhos de sol intenso e conta histórias. A afirmação pela narrativa, a afirmação solar da vida para além do trauma.

Eu conheci você antes que você pudesse andar [...]. Agora você tá de volta em casa [...]. Olhe pra você mesma. Você é livre, nada nem ninguém é obrigado a te salvar, a não ser você mesma. Semeie sua própria terra (2012, p. 125-126, tradução nossa).

Morrison semeia o seu chão-território nesse processo de construção ambivalente de personagens que ela deseja e odeia ao mesmo tempo; entre uns e outros, a sua possibilidade de existência subjetiva em trânsito se afirma pelo sol em seu lar, que não é tranquilo ou confortável; ao contrário, é intenso, mas é ao mesmo tempo sol e lar.

Elaine Potter Richardson - nascida em Antígua - insular nação caribenha, só "liberta" do jugo oficial inglês em 1981 (anteontem, portanto); mulher negra, pobre e anglófona migra, ainda aos 17 anos, para Nova York, onde assume um serviço de au pair. Nunca mais volta, não responde as cartas de casa, não manda dinheiro. Transforma-se na escritora Jamaica Kincaid. Escreve coisas lindas! Ganha prêmios importantes. Escreve para revistas influentes. Torna-se professora universitária de criação literária. Recomecemos... mulher negra, pobre e anglófona migra para Nova York... Não pensem que se trata de evolução 
individual. O que há é repetição subjetiva. Eterno retorno. O que há é o mecanismo da dobra. Vejamos como sua ficção opera o tal dispositivo...

Em seu último romance, See now then (Ver agora então, publicado em 2013, décadas depois da migração), ela consegue escrever:

$\mathrm{Eu}$ aceitei o amor que ela me deu sem dedicar-lhe qualquer pensamento e tomei pra mim como de direito uma vida que apenas me agradasse; então minha mãe teve raiva de mim porque eu não a amei também e teve ainda mais raiva porque eu não me tornaria ela. Eu tinha uma ideia de que me tornaria eu mesma; ela teve raiva pelo fato de que eu pudesse ter um eu, um ser separado que nunca pudesse ser conhecido por ela (Kincaid, 2013, p. 29, tradução nossa).

Essa é a mesma escritora que intitulara um de seus livros Autobiography of my mother (2013 [1996]) (Autobiografia de minha mãe), falando da mãe-nação partida de quem se espera total identificação até o limite do autoapagamento e, portanto, da morte, mas de quem não se pode desvincular; corpo híbrido, inorgânico, cuja sintomatologia se dá na escrita. Essa é a mesma escritora que continua a falar de uma mãe que a ensinara a ler, muito embora não lhe tivesse dado garantia da existência de uma memória integralizadora de sujeito. No bioficcional Autobiography of my mother, Kincaid já havia escrito:

Eu não me lembro de ter aprendido o alfabeto, as letras $A B$ e $C$ uma após a outra na sequência com todas as outras que terminam no Z. Eu só consigo enxergar agora que as letras se transformam em palavras e que as palavras encontram meus olhos e meus olhos as dão de comer aos meus lábios e então entre a escuridão de meus olhos impenetráveis e meus lábios está a forma do caos antes que a tirania da ordem seja imposta a elas, é onde me encontro, meu verdadeiro eu, de onde escrevo (2013 [1996], p. 29-30, tradução nossa).

O eu fragmentado que possibilita a escrita, demanda a escrita, move a escrita, não ao contrário - a escrita suplementar de uma fratura exposta na interposição narrativa da primeira pessoa -, vem movendo a produção literária de Kincaid desde esse trabalho mais nitidamente bioficcional de Autobiography e se radicaliza agora em See now then, narrativa na qual o olhar odioso do marido músico (ponto de conexão não sutil com a vida da escritora) constitui o olhar de fora - em terceira pessoa - que estrutura a sua desterritorialização. A narradora da própria vida, que aparece intermitentemente ao longo do romance está 
sempre fora de lugar. Se lembrarmos da definição de Edward Said para a chamada "leitura contrapontual":

A questão é que a leitura contrapontual precisa dar conta de ambos os processos, de imperialismo e resistência, o que pode ser feito estendendo nossa leitura de textos para incluir o que foi em algum momento forçosamente excluído (Said, 1993, p. 66-67, tradução e grifo nossos).

A inscrição autoficcional de Jamaica Kincaid/Elaine Potter Richardson interpela a tecnologia estética tão útil ao império inglês seu romance realista do século XIX, que tinha como órbita de representação o indivíduo burguês - executando uma leitura de si contrapontual e ruidosa ao jogo colonial de silenciamentos.

Bessie Emery Head, sul-africana, filha do apartheid entre mãe branca e pai negro quando as relações inter-raciais eram ali legalmente interditadas, fica órfã muito cedo, quando sua mãe tem um colapso mental. Depois de exilada em Botswana, começa a escrever e dar aulas, sempre com muito pouca infraestrutura material, vivendo entre pequenas vilas e ações contraoficiais e, em seguida, passa por um internamento em uma instituição psiquiátrica. A partir de então, escreve o romance $A$ question of power (Uma questão de poder), publicado em 1970.

O início do quarto capítulo do Atlântico negro, de Paul Gilroy, parece ter sido feito sob encomenda para o comentário crítico desse romance de Head. Na falta dessa conexão, não falta alguém que, reatravessando o Atlântico, possa fazê-lo:

O que foi inicialmente sentido como uma maldição, a maldição da ausência de lugar ou do exílio forçado - é reapropriado. Torna-se afirmativo e é reconstruído como uma posição privilegiada a partir da qual percepções críticas e estratégicas sobre o mundo moderno tornam-se mais plausíveis. Deveria ser óbvio que esta perspectiva incomum tenha sido forjada a partir das experiências de subordinação racial. Eu quero sugerir que ela também representa uma resposta aos deslocamentos, migrações e viagens sucessivas (forçadas ou não) que passaram a constituir estas condições especiais de existência das culturas negras (Gilroy, 1993, p. 111, tradução nossa).

Em A question of power, Head opera com uma narrativa vertiginosa que transita entre lugares de fala de racionalidade e irracionalidade/sanidade e loucura, primeira e terceira pessoas, perspectivas adulta e infantil/vozes 
de fé e ceticismo/representação realista e surreal. A técnica narrativa híbrida e em constante oscilação - sem índices de aviso prévio ao leitor e, posso imaginar, à própria escritora - constitui um catalisador de processo subjetivo em rede, em devir, em conexão, em influxo contínuos que não se deixam flagrar em formas fixas de personagens.

O sistema de relações entre os personagens e a narradora com uma possibilidade de "eu" é tão descontínuo quanto a sensação de que não temos pessoas palpáveis à mão, pessoas que conviveram com nossa leitura do percurso romanesco. Simplesmente, não há percurso; há ciclos espiralados, como a própria história das Áfricas e seu imaginário mítico latente, recalcado pelos textos eurocêntricos da cultura colonial.

A poesia entrelaçada à narrativa funciona como dispositivos de "desestanque" de um sangue paralisado em um "eu" impossível; que jorra, em cenas impiedosamente construídas de sexo feroz, morte, violência física, insanidade e amor filial. Aqui a narrativa é feita para fazer o sujeito fluido valer, sem que seja pensado como um quase nada liquefeito na "insanidade" como categoria de uso e abuso da nossa conhecida "civilização ocidental", assim como a valida a crítica literária de onde vem o seguinte fragmento:

Talvez, por ter sido penosamente consumida por seus desatinos, Bessie Head tenha conseguido descrever detalhes, nuances de uma crise, surto ou pesadelo; talvez tenha sido absorvida pelos desatinos de tal forma que lhe tenha sido possível nomear e descrever apenas de diferentes maneiras o que sentia (Silva, 2014, p. 50).

Os múltiplos usos possíveis do que antes tangenciei como "deslimites do eu", para referir-me ao bioficcional como funcionamento ético-estético de nossa cultura contemporânea, podem ser lidos como um relevo estriado e acidentado com diversas encruzilhadas, becos sem saída, bem como altitudes e latitudes plurivocais. Os usos que aqui me interessam - aqueles que se encontram no nó da produção subjetiva de experiências que se conectam intensamente a regimes de subalternização pós-escravista e pós-colonial - parecem-me modos de produção subjetiva em desvio e, em vários pontos e simultaneamente, tensionadores dos esquemas de localização por gênero, raça-etnia, nacionalidade e classe social. E, muito embora pareçam tecnicamente funcionar como uma repetição de alguma categoria estética que imaginemos, têm potência para politicamente funcionar como inflexão em alguma instância de um 
conceito operatório e de práticas literárias que lhes justifica e cuja existência sustenta.

Essa instância mínima e invisível de inflexão é aquela com que desejo lidar sob o epíteto de "con(tra)temporâneo": uma linha de força de certas práticas que, para além de lidarem com a simultaneidade da tríade entre aquilo que está no próprio tempo, contra e $a$ seu favor, subrepticiamente fazem exceder aquele traço contrário, tensionador, deslocador das margens do pensamento, das representações e das produções cotidianas. ${ }^{7}$

Para Deleuze-leitor-de-Foucault: “O rasgão não é mais o acidente do tecido, mas a nova regra segundo a qual o tecido externo se torce, se invagina e se duplica" (Deleuze, 2005, p. 104). Se posso entender essa con(tra)temporaneidade como um rasgão multiplamente enrugado, feito de dobras de dobras, desejo pensá-la geopoliticamente como uma recapitalização tensionada das técnicas e práticas de um certo tempo um modo ininterrupta e intensivamente negociado de re-usar.

As escritoras sobre cujos romances ensaiei um discurso crítico me parecem investidas nesse movimento que excede o tecnicamente bioficcional - a suspensão do limite entre um eu e um outro, na fronteira entre real e ficção, como produto de valor no mercado dos bens literários. Quero mesmo pensar que a dobra de suas experiências subjetivas derivadas de regimes subalternizantes pós-coloniais, racistas e sexistas possibilita as duplas inscrições narrativas que se conectam àquilo que podemos, correndo novamente o risco da invisibilização por homogeneidade, chamar "bioficção".

No entanto, o que meu discurso crítico procura visibilizar a partir da técnica do close - uma aproximação crítica, uma intensificação do detalhe diferencial - é o ponto em que a dobra pós-moderna do subjetivo se torna dobra da dobra; ou seja, recapitalização da capitalização de uma experiência de sequestro subjetivo, envolvido nos esquemas de subalternização aqui em jogo.

Lidando com a problemática de uma reconvergência daquilo que pode ser entendido como divergência em um primeiro momento, Nelson Maca afirma o seguinte:

\footnotetext{
${ }^{7}$ Estou aqui obviamente me referindo à discussão do conceito de contemporaneidade, atravessada pelo pensamento nietzscheano sobre o "intempestivo", a partir da leitura do ensaio crítico de Giorgio Agambem - $O$ que é o contemporâneo? (2009), assim como da própria Segunda consideração intempestiva de Friedrich Nietzsche (2003).
} 
A Literatura Divergente é um instrumento circunstancial de luta para distinção e respectiva afirmação das diferenças - subjetivas e materiais - que parte de uma potência partilhada (divergência) e se consagra numa estética particular (convergência). Logo sua conformação estética e sua consequente aderência a um coletivo social (Literatura Convergente) não representam uma contradição, senão o sentido último do desejo de expressão de pertencimento e cidadania diferenciada que moveu a obra e seu agente em direção à prática de uma literatura transgressora, descolonizadora, experimental e prospectiva (Maca, 2012, s.p.).

Pensamento que nos leva a superafirmar que, ainda que possamos flagrar uma capitalização discursiva (convergência) de territórios simbólicos de produção subjetiva afro-diaspórica e pós-colonial na territorialização do conceito de "biofiç̧ão", o funcionamento da divergência discursiva constitui uma força desviante suficientemente potente para reterritorializá-lo estratégica, localizada e con(tra)temporaneamente.

A escritora contemporânea afro-brasileira Cidinha da Silva, cuja produção literária articula "etnicidade e gênero; relações sociais de dominação e diversidade cultural; sociabilidade hetero, monogâmica ou não, com homoerotismo, além da experimentação com formas narrativas que vão da crônica ao conto e à tradição oral" (Duarte, 2011, p. 461), escreve, no conto "Latinhas", o seguinte:

Minha editora pauta uma crônica-síntese sobre o Natal, o AnoNovo e o Carnaval, mas só as latinhas povoam minha cabeça sem ideias. Gente procurando latinhas em todos os cantos e praças, caçambas e bares, de tocaia nas mãos de quem bebe refrigerante $\mathrm{e}$ cerveja. Latinhas por todos os poros, samba triste no meu cocuruto (Silva, 2011, p. 58).

Essa escritora mineira da chamada literatura divergente, que eu quero "con(tra)temporânea", nos indicia um trabalho por se fazer em nossa crítica literária - o agenciamento de uma teia de diálogos menos bilaterais, inclusiva do eixo sul-sul, que ative na instância crítica a potência de nossas desterritorializações pós-coloniais e pós-escravistas, produtoras de tensionamentos nos esquemas de produção de subjetividades não apenas previsíveis, mas principalmente úteis. Será que desejamos movimentar esse tipo de crítica? Quem deseja movimentá-la? Quem pode fazê-la? Quem a faz? 
Voltando ao começo, finalizo minha inscrição no campo, sulcando interessada e estrategicamente um caminho para o poderoso fluxo da voz de Bessie Head:

Tem essa tal coisa do sofrimento de pessoas negras serem um sumário de tudo que filósofos e profetas já disseram, ela disse. Eles disseram: "Nunca pense em termos de Eu e Meu. Isso é a morte". Mas eles disseram isso assim belamente, sob a sombra de árvores sagradas. Não teve qualquer impacto geral sobre a humanidade. Foi para um círculo exclusivo de seguidores. As pessoas negras aprenderam isso abruptamente porque foram as vítimas vivas da ganância inspirada pelo Eu e pelo Meu e pelo vá pro inferno, cachorro! Onde vocês acham que estão suas almas, então, depois de séculos de sofrimento? Estão à frente de Bhuda e Jesus e podem ditar os termos do futuro, não apenas para um círculo exclusivo, mas para a humanidade (Head, 1974, p. 134, grifo nosso).

\section{Referências}

AGAMBEM, Giorgio (2009). O que é o contemporâneo? e outros ensaios. Tradução de Vinícius Nicastro Honesko. Chapecó: Argos.

ARFUCH, Leonor (2010). O espaço biográfico: dilemas da subjetividade contemporânea. Tradução de Paloma Vidal. Rio de Janeiro: Editora UERJ.

ASHCROFT, Bill et al. (1989) The empire writes back: theory and practice in postcolonial literatures. London: Routledge.

BHABHA, Homi (2003). O local da cultura. Tradução de Myriam Ávila et al. Belo Horizonte: Editora UFMG.

CANCLINI, Néstor García (2005). Diferentes, desiguais e desconectados. Rio de Janeiro: Editora UFRJ.

CARRASCOSA, Denise (2009). Técnicas e politicas de si nas margens: seus monstros e heróis, seus corpos e declarações de amor. Tese (Doutorado em Letras) - Universidade Federal da Bahia, Salvador.

DELEUZE, Gilles (2005). Foucault. Tradução de Claudia Sant'Anna Martins. São Paulo: Brasiliense.

DUARTE, Constância Lima (2011). Cidinha da Silva. In: DUARTE, Eduardo de Assis (Org.). Literatura e afrodescendência no Brasil: antologia crítica. Belo Horizonte: Editora UFMG. (v. 3, Contemporaneidade.) 
FANON, Frantz (2008). Pele negra, máscaras brancas. Tradução de Renato da Silveira. Salvador: Editora UFBA.

FOUCAULT, Michel (1997). Resumo dos cursos do Collège de France (1970-1982). Tradução de Andréa Daher. Rio de Janeiro: Jorge Zahar.

GILROY, Paul (1993). The black Atlantic: modernity and double consciousness. Cambridge, Massachussets: Harvard University Press.

HEAD, Bessie (1974). A question of power. Edinburgh, Harlow, Essex: Heinemann. KINCAID, Jamaica (2013 [1996]). Autobiography of my mother. New York: Faber \& Faber.

KINCAID, Jamaica (2013). See now then. New York: Farrar; Strausand Giroux.

LEJEUNE, Philippe (2008). O pacto autobiográfico: de Rousseau à internet. Tradução e organização de Jovita Maria Gerheim Noronha e Maria Inês Coimbra Guedes. Belo Horizonte: Editora UFMG.

MACA, Nelson (2012). Manifestação da literatura divergente/ou/manifesto encruzilhador de caminhos. Salvador: Bahia Preta. Mimeo.

MORRISON, Toni (1990). The bluest eye. London: Pan Books.

MORRISON, Toni (2012). Home. New York: Vintage.

NIETZSCHE, Friedrich (2003). Segunda consideração intempestiva: da utilidade e desvantagem da história para a vida. Tradução de Marco Antônio Casanova. Rio de Janeiro: Relume Dumará.

SAID, Edward (1993). Culture and imperialism. New York: Vintage Books.

SILVA, Cidinha da (2011). Oh, margem! Reinventa os rios! São Paulo: Selo Povo.

SILVA, Patrícia Carla Freitas da (2014). Desatinos, discurso e poder: a partir de fragmentos do romance A question of power de Bessie Head. Trabalho de Conclusão de Curso (Bacharelado em Letras) - Universidade Federal da Bahia, Salvador.

SODRÉ, Muniz (2002). Antropológica do espelho: uma teoria da comunicação linear em rede. Petrópolis, Rio de Janeiro: Vozes.

Recebido em junho de 2014.

Aprovado em setembro de 2014. 


\section{resumo/abstract}

\section{Pós-colonialidade, pós-escravismo, bioficção e con(tra)temporaneidade}

\section{Denise Carrascosa}

Este ensaio crítico promove uma conexão entre o conceito contemporâneo do campo da teoria literária - bioficção -, a teoria pós-colonial e a problemática da subjetivação afro-diaspórica, a partir do local brasileiro de experiência histórica e possibilidade de fala intelectual, cruzado com um estudo sintomal dos últimos romances de Toni Morrison, Home (2012), e de Jamaica Kincaid, See now then (2013), bem como do romance A question of power (1970), de Bessie Head. O conceito de bioficção é tensionado como zona de embate de forças relacionadas aos processos históricos de subalternização vinculados à colonização, à escravidão e suas reverberações, em sua potência de divergência discursiva e produção "con(tra)temporânea" de subjetividades.

Palavras-chave: con(tra)temporaneidade, pós-colonialidade, pós-escravismo, bioficção, subjetividade.

\section{Post-coloniality, post-slavery, biofiction and co(unter)temporaneity}

\section{Denise Carrascosa}

This critical essay promotes a connection between the contemporary concept from the literary theory field named "biofiction", the post-colonial theory and the issue of African-diasporic subjetivization, from the Brazilian historical experience and intellectual possibility of speech, crisscrossed with a symptomatic study of the last novels written by Toni Morrison, Home (2012), and Jamaica Kincaid, See now then (2013), as well as of the novel A question of power (1970) by Bessie Head. The concept of biofiction is problematized as a zone of forces related to the historical processes of subalternization linked to colonization, slavery and their reverberations, in its potential of discursive divergence and "co(unter)temporary" production of subjectivities.

Keywords: co(unter)temporaneity, post-coloniality, post-slavery, biofiction, subjectivity. 